\title{
Gold as a Hedge and a Diversifier: The Perspective from Lebanon
}

\author{
Samih Antoine Azar ${ }^{1}$ \\ ${ }^{1}$ Professor, Faculty of Business Administration \& Economics, Haigazian University, Mexique Street, Kantari, Beirut, \\ Lebanon \\ Correspondence: Samih Antoine Azar, Professor, Faculty of Business Administration \& Economics, Haigazian \\ University, Mexique Street, Kantari, Beirut, Lebanon. Tel: 96-11-349-230.
}

Received: November 23, 2015

Accepted: December 9, $2015 \quad$ Online Published: December 10, 2015

doi:10.5430/afr.v5n1p27

URL: http://dx.doi.org/10.5430/afr.v5n1p27

\begin{abstract}
The purpose of this paper is to find out whether gold, valued in Lebanese terms, is a hedge against losses in purchasing power, and whether it is a portfolio diversifier. Gold is found to be a partial hedge to consumer price inflation, a weak hedge to the depreciation of the domestic currency, and a modest hedge to commodity price changes, like oil prices. Although in a multiple regression context gold seems to be unrelated to US stock prices, converted to Lebanese pounds, the bivariate correlation is positive and high. The diversification properties of gold, when it is added to (1) oil, to (2) the DJIA, to (3) the Euro, to (4) a deposit in Lebanese pounds, or to (5) oil, the DJIA, the Euro and a deposit in Lebanese pounds, all together, are studied. It is found that the diversification benefits are rather substantial. The implied price of risk is commensurate with the one in the US financial market. Finally, gold volatility is asymmetrically affected by positive and negative shocks in gold prices, similar to the evidence elsewhere. But unlike the evidence elsewhere the volatility of gold responds strictly to positive shocks but not to negative shocks.
\end{abstract}

Keywords: Gold price, Hedge, Portfolio diversifier, Inflation, Foreign exchange rate, Oil, Dow Jones Industrial Average, Interest rates, Lebanon

JEL Classification Codes: G12, G15, F31, C32, C58.

\section{Introduction}

Gold does not provide income. The return on gold is merely from its price appreciation. According to the recent literature on the subject gold can serve many purposes (Baur and Lucey, 2010; Baur and McDermott, 2010). One, gold may be a hedge against losses in purchasing power, and may compensate for losses arising from price inflation, foreign exchange rate changes and other asset returns. This can be assessed if gold returns increase in tandem with price inflation or with a depreciation of the domestic currency on foreign exchange markets, or even with commodity price changes like oil. Two, gold may be a portfolio hedge. This implies that gold is on average either little correlated with other assets (weak hedge), or negatively correlated with these assets (strong hedge). In this case gold serves as a portfolio diversifier if held with other assets in a portfolio context. Three, gold may be a safe haven, defined as an asset with little or negative correlation with other assets only in times of high uncertainty (Baur and Lucey, 2010; Baur and McDermott, 2010; Ciner et al., 2010). High uncertainty is measured by low percentiles in probability distributions. Since the data in this paper is not daily but monthly low percentiles produce very few observations, making their use impractical.

Additionally, gold may be considered as an investment asset, backing up the domestic currency, when a central bank owns gold as part of its foreign reserves. Gold is also used in jewelry, and Oriental people are known to have a marked preference for gold jewelry that they consider to be an important store of value (Baur and McDermott, 2010). Therefore gold is a topic of interest to many economists, investors, business men, central bankers, policy makers, and the general public. This is true for all countries, and applies directly and especially to Lebanon.

The first purpose of this paper is to study the hedging properties of gold in Lebanon. The central concern is whether gold makes up for losses in purchasing power or other opportunity costs. For this, gold returns are related to the returns of other assets, like oil prices, foreign exchange rates, stock markets, and bond markets, and to consumer price inflation. It is expected that gold returns depend positively on these other asset returns and on price inflation, but negatively on the yields on bonds or interest rates. The reason for this last negative relation is that, as interest rates and borrowing costs rise, investment in gold becomes more expensive and both demand for gold and gold 
prices fall. Ciner et al. (2010) argue that such a negative relation is due to the fact that gold is a strong portfolio hedge against bond returns.

The second purpose of this paper is to evaluate the portfolio diversification benefits arising from holding gold together with other assets. Five cases are considered: a portfolio of gold with oil, with the DJIA stock market index, with the Euro, with a deposit in Lebanese pounds, and, finally, with all these four assets together.

The paper is organized as follows. In the next section, section 2, the econometric model that is used to check for the hedging properties of gold is presented. This model consists mainly of a multiple regression where all variables are $\log$ differenced, except for the interest rate which is taken as is. The log returns of the price of gold in Lebanese terms are run against the log returns of the other four independent variables: the derived Lebanese consumer price index, the euro exchange rate in Lebanese pounds, the US Dow Jones Industrial Average, converted to Lebanese terms, and the price of oil in Lebanese pounds. The regressions consist of estimating a conditional mean equation with these four independent variables to which is appended either a TARCH or an EGARCH model of the conditional variance. Section 3 acknowledges the source of the data. Section 4 and 5 provide for the empirical results. Stationarity of $\log$ returns is tested first. Then the joint regressions are estimated. Finally five different portfolios that contain gold together with the other variables are studied to assess the extent of diversification. The last section summarizes and concludes.

\section{The model}

The model consists of a conditional mean equation and a conditional variance equation. There is one conditional mean equation and two specifications of the conditional variance equations: the threshold GARCH, or TARCH, and the Exponential GARCH, or EGARCH. The conditional mean equation is as follows:

$$
\Delta\left(\ln \left(\text { goldlbp }_{t}\right)\right)=\alpha_{0}+\sum_{i=1}^{4} \alpha_{i} \Delta\left(\ln \left(X_{i t}\right)\right)+\alpha_{5} r_{t}+\varepsilon_{t}
$$

In equation (1) $l n$ is the natural $\log$, goldlbp $_{t}$ is the price of an ounce of gold in Lebanese pounds at time $t$, and $\Delta$ is the first-difference operator. The four independent variables (or $X_{i}$ ) are the consumer price index in Lebanon, the price of Brent oil in Lebanese pounds, the foreign exchange rate of the Euro against the Lebanese pound, and the US Dow Jones Industrial Average stock market index, converted into Lebanese pounds. Taking the first-differences of the logs is an approximate estimate of returns or percentages and are called log returns, or log percent changes. The variable $r_{t}$ stands for the average interest rate on deposits in Lebanese pounds in the Lebanese banking system at time $t$, and $\varepsilon_{t}$ is the error term at time $t$.

Since it will be documented later that all the underlying variables in regression equation (1), except for $r$, the interest rate, are non-stationary in log-levels, then the first-differences of these logs are unanticipated shocks or news, meaning that this regression can be considered to be an Arbitrage Pricing Theory or APT regression model (Ross, 1976).

As shown in Baur $(2009,2011)$ the conditional variance of US gold shows asymmetric effects, which are opposite to the leverage effect in stock returns (Black, 1978; Christie, 1985). Baur $(2009,2011)$ explains this asymmetric effect by claiming that positive shocks to gold prices mirror increased uncertainty in financial markets, which raises gold volatility. There are two ways to account for asymmetry: the TARCH and the EGARCH models. The first was introduced independently by Zakoïan (1994) and Glosten et al. (1993), while the second was proposed by Nelson (1991). Both models assume that the error term is heteroscedastic:

$$
\varepsilon_{t} \sim \text { i.i.d. }\left(0, \sigma_{t}^{2}\right)
$$

The TARCH model is as follows:

$$
\sigma_{t}^{2}=\omega+\beta_{1} \sigma_{t-1}^{2}+\beta_{2} \varepsilon_{t-1}^{2}+\beta_{3} I_{t-1} \varepsilon_{t-1}^{2}
$$

In equation (3) $I_{t-1}=1$ if $\varepsilon_{t-1}<0$ and 0 otherwise. The effect of positive shocks in the conditional mean equation on the conditional variance is $\beta_{2}$ while the effect of negative shocks is the sum $\beta_{2}+\beta_{3}$. The contrary leverage effect is that $\beta_{3}<0$. The EGARCH model is as follows:

$$
\ln \left(\sigma_{t}^{2}\right)=\omega+\gamma_{1} \ln \left(\sigma_{t-1}^{2}\right)+\gamma_{2} \frac{\varepsilon_{t-1}}{\sigma_{t-1}}+\gamma_{3}\left|\frac{\varepsilon_{t-1}}{\sigma_{t-1}}\right|
$$


In equation (4) the effect of positive shocks in the conditional mean equation on the conditional variance is the sum $\gamma_{2}+\gamma_{3}$, while the effect of negative shocks is $\gamma_{2}-\gamma_{3}$. The contrary leverage effect is that $\gamma_{3}>0$. Equation (4) is the one actually estimated by the statistical package used in this paper, and is not exactly the same as the specification of Nelson (1991). The difference is reflected in the constant term.

\section{The Data}

The data on the US price of an ounce of gold, denoted as "gold", is taken from the web site of EconStats. The data on the price of an ounce of gold in Lebanese pounds, denoted as "goldlbp", the foreign exchange rate of the Euro against the Lebanese pound, denoted as "euro", and the average interest rate on deposits in Lebanese pounds in the Lebanese banking system, denoted as "LBP rate", are all taken from the web site of the Banque du Liban, the central bank of Lebanon. Since the Banque du Liban reports a fixed foreign exchange of the US dollar against the Lebanese pound starting from December 1998 onward, which was an adjustable peg period, the US dollar time-varying rate is obtained by dividing the price of gold in Lebanese pounds by the price of gold in US dollars. This rate is denoted as "usd". The data on the US Consumer Price Index, denoted as "cpi", is taken from the web site of inflation.data.com. Assuming PPP, Purchasing Power Parity, the Lebanese price level is obtained by multiplying the US CPI ("cpi") by the price of the US dollar in Lebanon ("usd"). This is a good approximation because Lebanon is a very open economy, and therefore inflation is expected to be mostly imported. The data on the FOB Brent spot price in US dollars per barrel, denoted as "oil", is taken from the web site of the US Energy Information Administration (www.eia.gov). The data on the US Dow Jones Industrial Average stock index, denoted as "djia", is taken from the web site of EconStats. The data spans the monthly period from September 1985 to February 2011, i.e. 306 observations per variable.

\section{The Empirical Results: Regression Analysis}

Before presenting the empirical results from estimating the regression equation (1), the variables need to be tested for stationarity (see Table 1). Three different unit root tests are employed: ADF (Dickey and Fuller, 1979), KPSS (Kwiatkowski et al., 1992), and DF-GLS (ERS) (Elliott et al., 1996).

Table 1. Unit root tests with a constant and a trend

\begin{tabular}{lccc}
\hline & ADF test (p-values) & KPSS test & DF-GLS (ERS) test \\
\hline $\ln ($ goldlbp $)$ & $-5.289972(0.0001)$ & 0.260606 & -0.68985 \\
$\Delta(\ln ($ goldlb $))$ & - & 0.280965 & -6.94066 \\
$\ln ($ cpi*usd $)$ & $-5.400440(<0.0001)$ & 0.376299 & -2.93431 \\
$\Delta(\ln ($ cpi*usd $))$ & - & 0.246134 & -6.68769 \\
$\ln \left(\right.$ oil * $^{*}$ usd $)$ & $-3.312072(0.0662)$ & 0.234148 & -1.23909 \\
$\Delta\left(\ln \left(\right.\right.$ oil ${ }^{*}$ usd $\left.)\right)$ & $-12.22710(<0.0001)$ & 0.098566 & -12.0259 \\
$\ln ($ euro $)$ & $-5.749920(<0.0001)$ & 0.336775 & -0.45878 \\
$\Delta(\ln ($ euro $))$ & - & 0.260213 & -7.50178 \\
$L B P$ rate & $-4.686118(<0.0001)$ & 0.125075 & -1.53087 \\
$\Delta($ LBP rate $)$ & - & 0.078735 & -12.8727 \\
$\ln ($ djia*usd $)$ & $-5.194733(0.0001)$ & 0.437777 & -0.15114 \\
$\Delta\left(\ln \left(\right.\right.$ djia* disd $\left.^{*}\right)$ & - & 0.208482 & -7.27001 \\
\hline
\end{tabular}

Notes: The number of lags in all tests is selected by minimizing the Schwarz Information Criterion (SIC). The null hypothesis of the ADF and DF-GLS (ERS) tests is non-stationarity. The null hypothesis of the KPSS test is stationarity. The critical values for the KPSS test are $0.2160(1 \%), 0.1460(5 \%)$, and $0.1190(10 \%)$. The critical values for the DF-GLS (ERS) test are $-3.4703(1 \%)$, $-2.9094(5 \%)$, and $-2.60395(10 \%)$. The variable "goldlbp is the price of an ounce of gold in Lebanese pounds. The variable "cpi" stands for the US consumer price index. The variable "oil"stands for the US price of Brent oil. The variable "euro" stands for the foreign exchange rate of the Euro against the Lebanese pound. The variable "LBP rate" stands for the Lebanese average interest rate on deposits. The variable "djid" stands for the US Dow Jones Industrial Average. The variable "usd" stands for the foreign exchange rate of the US dollar against the Lebanese pound. The operator $\ln$ is for the natural logarithm. The operator $\Delta$ is for the first-difference.

According to the ADF test the null hypothesis of non-stationarity is rejected for all the log-level variables, except for the $\log$ of the price of oil in Lebanese pounds $\left(\ln \left(\right.\right.$ oil $\left.l^{*} u s d\right)$ ). These findings are theoretically unacceptable because 
asset prices are expected to follow random walks, meaning they should be non-stationary. The KPSS tests find all variables, whether in logs or in first-differences of the logs, non-stationary except for the first-difference of the $\log$ of the price of oil in Lebanese pounds and the Lebanese deposit interest rate. The latter outcome is theoretically attractive because the marginal product of capital, for which the interest rate is a proxy, is expected to be stationary. The last test seems to be the one that can be relied upon most. This test finds all log-level variables to be non-stationary and all differences in log variables to be stationary. The only drawback of this test is the evidence that the deposit interest rate is non-stationary. Based on all these tests it is assumed that the log-level variables are all non-stationary, that the deposit interest rate is stationary, and that the log returns are all stationary. This implies that the statistical relation in the regression equation (1) is a proper specification.

Table 2 presents the estimation of regression equation (1) with a TARCH model of the conditional variance (equation (3)). In the conditional mean equation all variables have significant coefficients except for the log returns of the DJIA priced in the Lebanese currency. It is expected that, for gold to be a perfect inflation hedge, a $1 \%$ increase in inflation should result in a $1 \%$ increase in the price of gold. However, the empirical results show that a $1 \%$ increase in the domestic inflation rate leads to only a $0.636 \%$ increase in the log returns of gold. Although this coefficient is significantly different from +1 , one must recall that the inflation rate is measured with error, because PPP may not hold perfectly, which introduces a measurement error problem in the estimation and this shows up as a downward-biased coefficient on inflation (see Verbeek, 2009). In the literature, Worthington and Pahlavani (2007) present evidence that gold is cointegrated with consumer prices, but they do not report the cointegrating vector. Thus, one cannot judge the extent of the hedging property of gold.

Other results are that a $1 \%$ increase in oil prices results in a $0.037 \%$ increase in gold log returns, and that a depreciation of the Lebanese pound by $1 \%$ leads to a $0.357 \%$ increase in gold log returns. Again this last coefficient is significantly different from +1 . Ciner et al. (2010) find also that gold is a hedge against dollar depreciation (see also Capie et al., 2005 and Marzo and Zagaglia, 2010). Hence at face value gold is a partial hedge to inflation, a weak hedge to the depreciation of the domestic currency, and a modest hedge to oil price changes.

Table 2. Multiple regression analysis explaining the log returns of the gold price in Lebanon with a TARCH specification of the conditional variance. The sample size consists of 305 monthly observations and spans the period from October 1985 to February 2011

\begin{tabular}{lll} 
& \multicolumn{2}{c}{ Conditional mean equation } \\
Variable & coefficient & coefficient \\
\hline Constant & $0.018704(3.48970)$ & $0.018797(3.49599)$ \\
$\Delta\left(\ln \left(\right.\right.$ cpi $*^{*}$ usd $\left.)\right)$ & $0.636133(9.54465)$ & $0.619998(11.9713)$ \\
$\Delta(\ln ($ oil $*$ usd $))$ & $0.036735(2.37487)$ & $0.037169(2.43174)$ \\
$\Delta(\ln ($ euro $))$ & $0.356692(7.33030)$ & $0.356078(7.38625)$ \\
$L B P$ rate/l1200 & $-1.723536(3.1910)$ & $-1.740901(3.22246)$ \\
$\Delta(\ln ($ djia*usd $))$ & $-0.017337(0.40285)$ & - \\
\hline
\end{tabular}

\begin{tabular}{lll} 
& \multicolumn{2}{c}{ Conditional variance equation } \\
Variable & coefficient & coefficient \\
\hline Constant & $0.000374(4.37394)$ & $0.000371(4.47065)$ \\
resid $(-1)^{\wedge} 2$ & $0.586542(4.17659)$ & $0.595962(4.27117)$ \\
resid $(-1)^{\wedge} 2($ resid $(-1)<0)$ & $-0.595176(4.23543)$ & $-0.603110(4.30079)$ \\
GARCH $(-1)$ & $0.378298(3.64856)$ & $0.377784(3.76451)$ \\
\hline
\end{tabular}

$\begin{array}{lll}\frac{\text { Adjusted R-Square }}{\text { Residuals diagnostics }} & 0.820182 & 0.820175 \\ \mathrm{Q}(6) & 0.153 & 0.151 \\ \mathrm{Q}(12) & 0.154 & 0.145 \\ \mathrm{Q}^{2}(6) & 0.158 & 0.158 \\ \mathrm{Q}^{2}(12) & 0.429 & 0.416 \\ \text { Jarque-Bera test }(1980,1987)^{2} & <0.000001 & 0.000001\end{array}$

Notes: Absolute t-statistics next to the coefficient estimates are in parenthesis. Q(k) is the p-value of the the Ljung-Box Q-statistic on the standardized residuals for a lag order $\mathrm{k}$ (Ljung and Box, 1978). $\mathrm{Q}^{2}(\mathrm{k})$ is the p-value of the the Ljung-Box Q-statistic on the 
squares of the standardized residuals for a lag order $\mathrm{k}$. The Jarque-Bera test gives the p-value of a normality test on the standardized residuals. See the notes under Table 1 for the definition of the variables and other information.

Finally, a $1 \%$ increase in the deposit interest rate leads to a $1.724 \%$ decrease in gold log returns. The negative relation is as expected, although its interpretation is controversial. The regression results excluding the DJIA variable are also shown in Table 2. The estimated coefficients on the variables vary little relative to the unconstrained version.

Also in Table 2 the results of the specification of the conditional variance are reported. As expected there is a strong asymmetric effect of gold price shocks. A positive shock in the log returns of gold affects the conditional variance positively. However a negative shock is neutral on the conditional variance because the sum $\beta_{2}+\beta_{3}$ in regression equation (3) is insignificantly different from zero ( $\mathrm{p}$-value $=0.9143$ ). Hence there is a strong and contrary leverage effect. The result that negative shocks are neutral on the conditional variance is not to be found in the literature and seems to be peculiar for Lebanon. The long run standard deviation for negative shocks in gold prices is $2.453 \%$ per month while that for positive shocks is $10.314 \%$ per month. The annualized standard deviations, applying the log-normal property, are $8.666 \%$ and $36.712 \%$ respectively.

The residual diagnostics reject serial correlation and heteroscedasticity of the standardized residuals. Hence the model seems to be well-specified and there is no need for dynamics, or for including lags in variables like in Ciner et al. (2010).

Table 3 presents the estimation of regression equation (1) with an EGARCH model of the conditional variance (equation (4)). In the conditional mean equation all variables have significant coefficients except for the log returns of the DJIA priced in the Lebanese currency. A $1 \%$ increase in inflation, in oil prices, and in the foreign exchange rate of the Euro leads to a $0.614 \%$, a $0.037 \%$, and a $0.375 \%$ increase in gold prices. Again gold is seen as a partial hedge to inflation, a weak hedge to the depreciation of the domestic currency, and a modest hedge to oil price changes.

Table 3. Multiple regression analysis explaining the log returns of the gold price in Lebanon with an EGARCH specification of the conditional variance. The sample size consists of 305 monthly observations and spans the period from October 1985 to February 2011

\section{Conditional mean equation}

\begin{tabular}{llc} 
Variable & coefficient & coefficient \\
\hline Constant & $0.019395(3.50609)$ & $0.019786(3.56443)$ \\
$\Delta(\ln ($ cpi $*$ usd $))$ & $0.614469(9.08613)$ & $0.593382(11.3820)$ \\
$\Delta(\ln ($ oil $*$ usd $))$ & $0.037023(2.29428)$ & $0.037078(2.32494)$ \\
$\Delta(\ln ($ euro $))$ & $0.375370(7.45947)$ & $0.377298(7.47261)$ \\
LBP rate $/ 1200$ & $-1.73568(3.09717)$ & $-1.78847(3.18131)$ \\
$\Delta\left(\ln \left(\right.\right.$ djia* $\left.\left.{ }^{\text {usd }}\right)\right)$ & $-0.02057(0.49054)$ & -
\end{tabular}

\begin{tabular}{lll} 
& \multicolumn{3}{l}{ Conditional variance equation } \\
Variable & coefficient & coefficient \\
\hline Constant & $-2.71487(4.35962)$ & $-2.71001(4.47527)$ \\
resid(-1)/@ sqrd(GARCH(-1)) & $0.269662(3.95662)$ & $0.274754(4.05802)$ \\
abs(resid(-1)/@sqr(GARCH(-1))) & $0.373145(3.47783)$ & $0.383778(3.57020)$ \\
$\ln ($ GARCH(-1)) & $0.652546(7.43494)$ & $0.654314(7.65351)$ \\
\hline
\end{tabular}

$\begin{array}{ll}\text { Adjusted R-Square } & 0.820264\end{array}$

$\underline{\text { Residuals diagnostics }}$

\begin{tabular}{lll}
\hline $\mathrm{Q}(6)$ & 0.144 & 0.139 \\
$\mathrm{Q}(12)$ & 0.162 & 0.152 \\
$\mathrm{Q}^{2}(6)$ & 0.130 & 0.129 \\
$\mathrm{Q}^{2}(12)$ & 0.373 & 0.358
\end{tabular}

$\begin{array}{lll}\text { Jarque-Bera test }(1980,1987) & 0.000001 & 0.000002\end{array}$

Notes: Absolute t-statistics next to the coefficient estimates are in parenthesis. See the notes under Table 1 for the definition of the variables. See the notes under Table 1 and under Table 2 for other information. 
Also in Table 3 the results of the specification of the conditional variance are reported. As expected there is a strong asymmetric effect of gold shocks. A positive shock in log returns of gold affects the conditional variance positively. However a negative shock is neutral on the conditional variance because $\gamma_{2}-\gamma_{3}$ in regression equation (4) is insignificantly different from zero ( $p$-value $=0.4527)$, a result which seems to be peculiar for Lebanon. Hence there is a strong and contrary leverage effect.

The residual diagnostics reject serial correlation and heteroscedasticity of the standardized residuals. Hence the model seems to be well-specified and there is no need for dynamics, like including lags in variables like in Ciner et al. (2010).

Tables 2 and 3 also show that, in all models, the explained variations by the independent variables, adjusted by the degrees of freedom, or adjusted R-Squares, are relatively high for monthly data, and range between $82.0136 \%$ and $82.0182 \%$.

In order to be comparable to Baur $(2009,2011)$ the regressions in Tables 2 and 3 are rerun with the assumption that the GARCH model follows a t-distribution, instead of a normal distribution. The results, which are not reported, show little changes in the coefficient estimates, and the same significant asymmetric effects. The estimated values of the degrees of freedom are $6.085(\mathrm{t}$-statistic $=2.352)$, and $6.314(\mathrm{t}$-statistic $=2.409)$ for the two models respectively. These estimates are close to the regression results in $\operatorname{Baur}(2009,2011)$ who reports a degree of freedom around 6 for his regressions.

\section{The Empirical Results: Diversification Benefits}

Table 4 provides descriptive statistics on all the variables. The annualized mean log returns vary between $25.80 \%$ and $34.29 \%$, except, of course, for the deposit interest rate. The annualized standard deviations, using the log-normal property, are closer to each other, and range between $24.41 \%$ and $27.16 \%$, except for the log returns of the oil price which have an annualized standard deviation of $42.09 \%$, and except, of course, for the deposit interest rate. This is evidence that oil is a highly volatile and speculative asset. A t-test on the means shows that all mean $\log$ returns are statistically significantly different from zero, including the mean of the deposit interest rate.

Table 4. Descriptive statistics. The number of monthly observations is 305, from October 1985 to February 2011, except for the LBP rate which has 306 monthly observations, from September 1985 to February 2011

\begin{tabular}{|c|c|c|c|c|c|c|}
\hline & $\Delta(\ln ($ goldlbp $))$ & $\Delta(\ln (c p i * u s d))$ & $\Delta(\ln ($ oil $* u s d))$ & $\Delta(\ln ($ euro $))$ & $\begin{array}{c}\angle B P \\
\text { rate/1200 }\end{array}$ & $\Delta\left(\ln \left(\right.\right.$ djia $\left.\left.^{*} u s d\right)\right)$ \\
\hline Mean & 0.019156 & 0.016755 & 0.018746 & 0.016250 & 0.009735 & 0.021701 \\
\hline $\begin{array}{l}\text { Annualized } \\
\text { mean }\end{array}$ & 0.303519 & 0.258189 & 0.361393 & 0.258024 & 0.116820 & 0.342928 \\
\hline Median & 0.004407 & 0.001415 & 0.022429 & 0.003571 & 0.010196 & 0.012504 \\
\hline $\begin{array}{l}\text { Standard } \\
\text { deviation }\end{array}$ & 0.076589 & 0.069057 & 0.118009 & 0.075875 & 0.003066 & 0.075763 \\
\hline $\begin{array}{l}\text { Annualized } \\
\text { standard } \\
\text { deviation }\end{array}$ & 0.271636 & 0.244134 & 0.420906 & 0.268301 & 0.01062 & 0.269366 \\
\hline Standard error & 0.004385 & 0.003954 & 0.006757 & 0.004345 & 0.000175 & 0.004338 \\
\hline Maximum & 0.367057 & 0.367581 & 0.607843 & 0.360079 & 0.017150 & 0.375216 \\
\hline $\begin{array}{l}\text { Minimum } \\
\text {-value of the }\end{array}$ & -0.278214 & -0.209943 & -0.324777 & -0.232050 & 0.004692 & -0.237980 \\
\hline $\begin{array}{l}\text { normality test } \\
\text { t-test statistic }\end{array}$ & $<0.000001$ & $<0.000001$ & $<0.000001$ & $<0.000001$ & 0.003113 & $<0.000001$ \\
\hline on the mean & 4.3681 & 4.2373 & 2.7742 & 3.7403 & 55.5424 & 5.0023 \\
\hline
\end{tabular}

Notes: The normality test is the Jarque-Bera test. See the notes under Table 1 for the definition of the variables. The annualized mean is obtained by multiplying the monthly mean (plus half the variance) by 12 , taking the exponential and subtracting one. The annualized standard deviation is obtained by multiplying the monthly standard deviation by the square root of 12 . The monthly standard deviation is adjusted to satisfy the log-normal property.

In Table 4, the log returns of the gold price have an average return of $30.35 \%$ per annum, while McCown and Zimmerman (2006) find that gold has the same average return as that of Treasury Bills, and Baur $(2009,2011)$ finds 
also an average return of only $3.7 \%$ for gold prices in US dollars. A $30.35 \%$ return in Lebanon means that gold has been a decent investment outlet over the period considered.

Since in the conditional mean equations (Tables 2 and 3) the coefficient on oil price changes is small and the coefficient on the DJIA log returns measured in Lebanese pounds is insignificantly different from zero, one may jump to the conclusion that forming a portfolio of gold, oil, and the DJIA index ought to have a very low variance. In other terms gold can be seen as a portfolio diversifier with oil and the DJIA index, and a partial hedge for inflation and for a depreciation of the domestic currency.

However a portfolio diversifier (Markowitz, 1952, 1959) should have a low or negative unconditional correlation coefficient with another asset and not a small or zero partial correlation coefficient in a multiple regression, as the coefficient on the DJIA variable. Incidentally, McCown and Zimmerman (2006) find also that gold in dollar terms is a zero-beta asset, even in an APT context, like the results in this paper. A zero-beta asset is an asset that has a slope coefficient that is insignificantly different from zero when its returns are regressed on the returns of a stock market index.

In order to make a well-advised judgment Table 5 reports bivariate correlation coefficients. The correlation coefficient of the $\log$ returns of the price of gold is 0.605 with the log returns of the price of oil, is 0.873 with the Euro, and is 0.744 with the log returns of the DJIA index. All these correlation coefficients are high, positive and statistically significantly different from zero.

The high and positive unconditional correlation coefficient between gold and the DJIA, converted to Lebanese pounds, contradicts the regression results whereby the log return of the DJIA in Lebanese terms has a partial correlation coefficient, or regression coefficient, that is statistically insignificantly different from zero. These high bivariate correlation coefficients, of oil, the Euro and the DJIA with gold, imply that Markowitz diversification of the total variance of a portfolio made up of gold and each of these assets separately may be limited, or even that a portfolio comprising all these three assets with gold has little diversification benefits. However, these are not true statements, as will be shown next.

Table 5. Correlation coefficients

\begin{tabular}{cllllll}
\hline & $\Delta(\ln ($ goldlbp $))$ & $\Delta(\ln ($ cpi*usd $))$ & $\Delta(\ln ($ oil $*$ usd $))$ & $\Delta(\ln ($ euro $))$ & LBP rate & $\Delta(\ln ($ djia*usd $))$ \\
\hline$\Delta(\ln ($ goldlb $))$ & 1 & & & & & \\
$\Delta(\ln ($ cpi*usd $))$ & 0.889903 & 1 & & & & \\
$\Delta\left(\ln \left(\right.\right.$ oil us $\left.\left.^{*}\right)\right)$ & 0.604959 & 0.604416 & 1 & & & \\
$\Delta(\ln ($ euro $))$ & 0.872641 & 0.915544 & 0.591370 & 1 & & \\
LBP rate & 0.152723 & 0.263725 & 0.107345 & 0.230094 & 1 & \\
$\Delta(\ln ($ djia*usd $))$ & 0.743938 & 0.865622 & 0.502258 & 0.789519 & 0.276799 & 1 \\
\hline
\end{tabular}

Notes: The critical correlation coefficient for a $1 \%$ upper-tail marginal significance level is 0.133231 . See the notes under Table 1

for the definition of the variables.

In fact one cannot consider oil as a bad portfolio diversifier with gold just by looking at the bivariate correlation coefficient even though the log returns of the price of oil have such a high standard deviation, almost double the standard deviation of other assets with comparable mean log returns. For example, a 50/50 investment in gold and oil produces a portfolio average return and standard deviation of $33.246 \%$ and $31.197 \%$ respectively while a 90/10 investment produces a portfolio average return and standard deviation of $30.931 \%$ and $27.201 \%$ respectively. These statistics are similar to those of an investment in gold alone.

Markowitz diversification of the total variance of a portfolio made up of gold and the DJIA index is now studied. The average log returns of gold (30.352\%) is less than that of the DJIA index (34.293\%) but their standard deviations are trivially different at $27.164 \%$ and $26.937 \%$ respectively, implying that an investment in the DJIA dominates an investment in gold. A portfolio made up of these two assets may be worthwhile although their correlation coefficient is rather high (0.744). A 50/50 investment in gold and the DJIA index produces a portfolio average return and standard deviation of $32.322 \%$ and $25.259 \%$ respectively. This combination dominates an investment in gold alone. The same conclusion arises when the investment is 90/10 or 10/90 in gold and the DJIA index. For the former investment (90/10) the portfolio average return is $30.746 \%$ and the portfolio standard deviation is $26.512 \%$. For the latter investment (10/90) the portfolio average return and the portfolio standard deviation are $33.899 \%$ and $26.326 \%$ respectively. These results run against the evidence in Ciner et al. (2010) but are consistent with the conclusions of Ratner and Klein (2008). 
As for a portfolio made up of gold and the Euro, the following results can be obtained. A 50/50 investment has a portfolio average return and standard deviation equal to $28.077 \%$ and $26.123 \%$ respectively. This portfolio dominates an investment in the Euro alone, as does a 90/10 portfolio investment. Compared to gold alone these two portfolios do not have any clear dominance. Therefore a portfolio made up of gold and the Euro improves upon an investment in the Euro alone but not upon an investment in gold alone.

The asset that seems most attractive to be jointly held with gold is a bank deposit in Lebanese pounds. The correlation coefficient between the two is only 0.153 but is nonetheless significantly different from zero (t-statistic $=$ 2.694). Table 6 summarizes the impact of varying portfolio weights on a portfolio made up of gold and a deposit in Lebanese pounds. The portfolio annual average return goes from $12.40 \%$ to $30.35 \%$ in positive increments. The portfolio annual standard deviation also increases in positive increments from $1.07 \%$ to $27.16 \%$.

A salient feature of Table 6 , besides the diversification benefits, is that the relation between the portfolio annual average return and the annual variance of returns is non-linear, as expected, while the relation between the portfolio annual average return and the annual standard deviation of returns is almost linear. A regression of the portfolio average return on the portfolio standard deviation produces a slope of 0.67294 (t-statistic $=64.711)$, a constant of 0.11299 (t-statistic $=68.445$ ), an adjusted R-Square of 0.99525, a quasi perfect fit, and a p-value for the heteroscedasticity F-test of Harvey of 0.7764, rejecting heteroscedasticity. Such a slope (0.67294), which measures the price of risk in a Capital Market Line context, or the reward-to-variability ratio, or even the market Sharpe ratio, is close to the price of risk in the US financial market. See, for example, Bodie et al. (2009), Azar (2010), or Ross et al. (2010) where the estimates vary between 0.33 and 0.91 .

Table 6. Effects on portfolio average return and on portfolio standard deviation of varying portfolio weights for an investment in gold and in a deposit in Lebanese pounds

\begin{tabular}{ccccc}
\hline Share in gold & $\begin{array}{c}\text { Average } \\
\text { return of portfolio }\end{array}$ & $\begin{array}{c}\text { Standard deviation } \\
\text { of portfolio }\end{array}$ & $\begin{array}{c}\text { Return } \\
\text { (yearly) }\end{array}$ & $\begin{array}{c}\text { Standard deviation } \\
\text { (yearly) }\end{array}$ \\
\hline 0.00 & 0.009735 & 0.003066 & 0.123980 & 0.010725 \\
0.05 & 0.010207 & 0.005156 & 0.130481 & 0.018045 \\
0.10 & 0.010678 & 0.008530 & 0.137204 & 0.029868 \\
0.15 & 0.01149 & 0.012164 & 0.144166 & 0.042614 \\
0.20 & 0.011620 & 0.015880 & 0.151371 & 0.055663 \\
0.25 & 0.012091 & 0.019631 & 0.158822 & 0.068851 \\
0.30 & 0.012562 & 0.023402 & 0.166526 & 0.082125 \\
0.35 & 0.013033 & 0.027183 & 0.174485 & 0.095453 \\
0.40 & 0.013550 & 0.030971 & 0.183363 & 0.108829 \\
0.45 & 0.013975 & 0.034763 & 0.191188 & 0.122228 \\
0.50 & 0.014446 & 0.038559 & 0.199941 & 0.135667 \\
0.55 & 0.014917 & 0.042357 & 0.208970 & 0.149135 \\
0.60 & 0.015388 & 0.046157 & 0.218279 & 0.162632 \\
0.65 & 0.015859 & 0.049958 & 0.227872 & 0.176155 \\
0.70 & 0.016330 & 0.053761 & 0.237758 & 0.189711 \\
0.75 & 0.016801 & 0.057564 & 0.247939 & 0.203291 \\
0.80 & 0.017272 & 0.061368 & 0.258424 & 0.216900 \\
0.85 & 0.017743 & 0.065172 & 0.269217 & 0.230537 \\
0.90 & 0.018214 & 0.068978 & 0.280327 & 0.244209 \\
0.95 & 0.018685 & 0.072783 & 0.291758 & 0.257906 \\
1.00 & 0.019156 & 0.076589 & 0.303519 & 0.271636 \\
\hline
\end{tabular}

Notes: The annualized mean is obtained by multiplying the monthly mean (plus half the variance) by 12 , taking the exponential and subtracting one. The annualized standard deviation is obtained by multiplying the monthly standard deviation by the square root of 12 . The monthly standard deviation is adjusted to satisfy the log-normal property.

The deposit in Lebanese pounds is also attractive as a diversifier with oil, the DJIA, and the Euro, all three in Lebanese terms, because their correlation coefficients with the deposit rate are quite low at $0.1073,0.2768$, and 0.2301 respectively. Hence, a priori, a portfolio made up of gold, the deposit, oil, the DJIA and the Euro might be 
worthwhile. Table 7 presents an analysis of such a portfolio. Table 7 is constructed as follows. Once the share in gold is specified, the other four shares are assumed to be equal within the remaining share. For example a share of $10 \%$ in gold leaves a share of $22.5 \%$ in each asset of the other four assets. This methodology is adopted to highlight the diversification benefits of gold, which is the concern of this paper.

Table 7 shows that, as the share in gold is increased, the annualized return rises from $24.57 \%$, when gold is excluded, to $30.35 \%$, when the investment is totally in gold, in small increments. Similarly the volatility of the portfolio rises from $20.59 \%$ to $27.16 \%$ also in small increments. In Table 7 the gains in reducing the portfolio standard deviation are less than those in Table 6. However, the gains in increasing the portfolio average return are higher in Table 7 relative to Table 6 . As expected, the relation between the average returns of the portfolios and the variance of portfolio returns is non-linear. But the relation between the average returns of the portfolios and the standard deviation of portfolio returns is almost linear. A regression of the former on the latter, in annualized terms, produces a slope of 0.8536 (t-statistic $=47.218$ ), an intercept of 7.385\% (t-statistic $=17.512)$, an adjusted R-Square of 0.9911, and a p-value for the heteroscedasticity F-test of Harvey of 0.9477 , rejecting heteroscedasticity. Such a slope $(0.8536)$ is a measure of the price of risk in a Capital Market Line, of the reward-to-volatility ratio, and of the market Sharpe ratio. Again, as for the results on Table 6, this slope is close to values in the US financial market. See, for example, Bodie et al. (2009), Azar (2010), or Ross et al. (2010) where the estimates vary between 0.33 and 0.91 .

Table 7. Effects on portfolio average return and on portfolio standard deviation of varying portfolio weights of gold for an investment in gold, in a deposit in Lebanese pounds, in oil in Lebanese pounds, in the DJIA stock market index in Lebanese pounds, and in the foreign exchange rate of the Euro in Lebanese pounds

\begin{tabular}{ccccc}
\hline Share in gold & $\begin{array}{c}\text { Average } \\
\text { return of portfolio }\end{array}$ & $\begin{array}{c}\text { Standard deviation } \\
\text { of portfolio }\end{array}$ & $\begin{array}{c}\text { Return } \\
\text { (yearly) }\end{array}$ & $\begin{array}{c}\text { Standard deviation } \\
\text { (yearly) }\end{array}$ \\
\hline 0.00 & 0.016608 & 0.058307 & 0.245696 & 0.205888 \\
0.05 & 0.016736 & 0.058622 & 0.247886 & 0.207033 \\
0.10 & 0.016863 & 0.059013 & 0.250135 & 0.208447 \\
0.15 & 0.016990 & 0.059477 & 0.252454 & 0.210122 \\
0.20 & 0.017118 & 0.060014 & 0.254863 & 0.212056 \\
0.25 & 0.017245 & 0.060622 & 0.257330 & 0.214243 \\
0.30 & 0.017373 & 0.061297 & 0.259884 & 0.216670 \\
0.35 & 0.017500 & 0.062039 & 0.262499 & 0.219336 \\
0.40 & 0.017627 & 0.062844 & 0.265187 & 0.222227 \\
0.45 & 0.017755 & 0.063711 & 0.267967 & 0.225340 \\
0.50 & 0.017882 & 0.064636 & 0.270805 & 0.228661 \\
0.55 & 0.018010 & 0.065618 & 0.273736 & 0.232187 \\
0.60 & 0.018137 & 0.066653 & 0.276727 & 0.235903 \\
0.65 & 0.018265 & 0.067740 & 0.279811 & 0.239808 \\
0.70 & 0.018392 & 0.068876 & 0.282957 & 0.243889 \\
0.75 & 0.018519 & 0.070058 & 0.286180 & 0.248136 \\
0.80 & 0.018647 & 0.071284 & 0.289497 & 0.252544 \\
0.85 & 0.018774 & 0.072553 & 0.292879 & 0.257107 \\
0.90 & 0.018902 & 0.073861 & 0.296355 & 0.261814 \\
0.95 & 0.019029 & 0.075207 & 0.299896 & 0.266659 \\
1.00 & 0.019156 & 0.076589 & 0.303519 & 0.271636 \\
\hline
\end{tabular}

Notes: The annualized mean is obtained by multiplying the monthly mean (plus half the variance) by 12 , taking the exponential and subtracting one. The annualized standard deviation is obtained by multiplying the monthly standard deviation by the square root of 12 . The monthly standard deviation is adjusted to satisfy the log-normal property.

\section{Conclusion}

This paper has two major goals: assessing whether gold is a hedge that compensates for losses in purchasing power, and finding out whether gold can serve as a portfolio diversifier. The first goal implies that gold returns should move 
in tandem with variables measuring purchasing power. In this regard gold is empirically found to be a partial hedge to consumer price inflation, a weak hedge to currency depreciation, and a modest hedge to commodity price changes, like oil price changes.

The second goal, i.e. the diversification property, is reached if gold is little or negatively correlated with other assets. Correlation coefficients are high and positive providing a priori little basis for diversification. Only the correlation coefficient of gold with a bank deposit in Lebanese pounds is close to zero. A portfolio made up of gold and a deposit in Lebanese pounds is studied extensively by varying the share of investment in gold. In addition, portfolios of gold with oil alone, with the DJIA alone, with the Euro alone, and with oil, the DJIA, the Euro and a deposit in Lebanese pounds, all together, are assessed. It is clear from the analysis that there are substantial diversification benefits.

As a general conclusion gold is a reasonable stand-alone investment outlet, carries some hedging properties, and appears to be an adequate portfolio diversifier with oil, the DJIA stock market index, the Euro, and a deposit in Lebanese pounds. Finally, similar to the evidence elsewhere, the volatility of the returns of gold is strongly asymmetric responding more to positive shocks than to negative ones. However, in the case of Lebanon, negative shocks do not impact significantly the volatility. Such a feature seems to be peculiar to Lebanon.

The added value of this paper is fourfold. One, the topic has not interested other researchers in Lebanon. In this respect the paper is exclusive. Second, the paper has revealed a different behavior of the volatility of gold than elsewhere. Three, the market price of risk in Lebanon is commensurate with the one in foreign markets. All in all the paper has provided evidence that the glamour of gold is fully justified for its hedging and diversification benefits.

One major limitation to this study is the fact that the portfolio mixes that were constructed do not ensure that they fall on the Markowitz efficient frontier. This means that diversification properties that were derived from the mixes underestimate the true diversification benefits. The paper therefore identifies a lower bound for these benefits, which implies that gold is in reality more attractive for diversification than has been shown. Another limitation, which stems from the same general idea, is that it is difficult, if not impossible, to compare the diversification benefits uncovered here with the literature because the latter does not examine arbitrary portfolio weights as this study has done. Thus an avenue for future research is to repeat the calculations carried out here, especially in what concerns the arbitrary weights, to similar situations in the developed and the developing worlds.

\section{References}

Azar, S. (2010). Markowitz diversification and the foreign exchange rate exposure of banks. Banking and Finance Letters, 2, 229-239.

Baur, D. G. (2009). The volatility of gold. Accessed by Google Scholar, conference paper, efmaefm.org, pp. 1-27.

Baur, D. G. (2011). Asymmetric volatility in the gold market. Available at SSRN: http://ssrn.com/abstract=1526389, pp. 1-29. http://dx.doi.org/10.2139/ssrn.1526389

Baur, D. G. \& Lucey, B. M. (2010). Is gold a safe haven? An analysis of stocks, bonds, and gold. The Financial Review, 45, 217-229. http://dx.doi.org/10.1111/j.1540-6288.2010.00244.x

Baur, D. G. \& McDermott, T. K. (2010). Is gold a safe haven? International evidence. Journal of Banking and Finance, 34, 1886-1898. http://dx.doi.org/10.1016/j.jbankfin.2009.12.008

Black, F. (1976). Studies of stock price volatility changes. Proceedings of the American Statistical Association, Business and Economic Statistics Section, 177-181.

Bodie, Z., Kane, A., \& Marcus, A. J. (2009). Investments ( $8^{\text {th }}$ edition). Boston: McGraw-Hill.

Capie, F., Mills, T. C., \& Wood, G. (2005). Gold as a hedge against the dollar. Journal of International Financial Markets, Institutions and Money, 15, 343-352. http://dx.doi.org/10.1016/j.intfin.2004.07.002

Christie, A. A. (1982). The stochastic behavior of common stock variances: value, leverage and interest rates effects. Journal of Financial Economics, 10, 407-432. http://dx.doi.org/10.1016/0304-405X(82)90018-6

Ciner, C., Gurdgiev, C. \& Lucey, B. M. (2010). Hedges and safe havens - An examination of stocks, bonds, oil, gold and the dollar. Institute for International Integration Studies, IIS discussion paper No 337.

Dickey, D.A. \& Fuller, W. A. (1979). Distribution of the estimators for autoregressive time series with a unit root. Journal of the American Statistical Association, 74, 427-431. http://dx.doi.org/10.2307/2286348. http://dx.doi.org/10.1080/01621459.1979.10482531 
Elliott, G., Rothenberg, T.J. \& Stock, J.H. (1996). Efficient tests for an autoregressive unit root. Econometrica, 64, 813-836. http://dx.doi.org/10.2307/2171846

Glosten, L.R., Jagannathan, R. \& Runkle, D. E. (1993). On the relation between the expected value and the volatility of the normal excess return on stocks. Journal of Finance, 48, 1779-1801.http://dx.doi.org/10.1111/j.1540-6261.1993.tb05128.x

Jarque, C. M. \& Bera, A. K. (1980). Efficient tests for normality, homoskedasticity and serial dependence of regression residuals. Economics Letters, 6, 255-259. http://dx.doi.org/10.1016/0165-1765(80)90024-5

Jarque, C. M. \& Bera, A. K. (1987). A test for normality of observations and regression residuals. International Statistical Review, 55, 163-172. http://dx.doi.org/10.2307/1403192

Kwiatkowski, D., Phillips, P. C., Schmidt, P., \& Shin, Y. (1992). Testing the null hypothesis of stationarity against the alternative of a unit root. Journal of Econometrics, 54, 159-178. http://dx.doi.org/10.1016/0304-4076(92)90104-Y

Ljung, G. M. \& Box, G. E. P. (1978). On a measure of a lack of fit in time series models. Biometrika, 65, $297-303$. http://dx.doi.org/10.1093/biomet/65.2.297

Markowitz, H. (1952). Portfolio Selection. Journal of Finance, 7, 77-91. http://dx.doi.org/10.1111/j.1540-6261.1952.tb01525.x. http://dx.doi.org/10.2307/2975974

Markowitz, H. (1959). Portfolio selection. New York: John Wiley \& Sons.

Marzo, M. \& Zagaglia, P. (2010). Gold and the U.S. dollar: Tales from the turmoil. Munich Personal RePEc Archive, MRPA paper, available at http://mpra.ub.uni-muenchen.de/22407/, pp. http://dx.doi.org/10.2139/ssrn.1598745

McCown, J. M., \& Zimmerman, J. R. (2006). Is gold a zero-beta asset? Analysis of the investment potential of precious metals. Available at SSRN: http://ssrn.com/abstract=920496.

Nelson, D.B. (1991). Conditional heteroskedasticity in asset returns: a new approach. Econometrica, 59, 347-370. http://dx.doi.org/10.2307/2938260

Ratner, M. \& Klein, S. (2008). The portfolio implications of gold investment. The Journal of Investing, Spring, 77-87. http://dx.doi.org/10.3905/joi.2008.701958

Ross, S. (1976). The arbitrage theory of capital asset pricing. Journal of Economic Theory, 13, 341-360. http://dx.doi.org/10.1016/0022-0531(76)90046-6

Ross, S. A., Westerfield, R. W. \& Jaffe, J. F. (2010). Corporate finance (9 $9^{\text {th }}$ edition). Boston: McGraw-Hill.

Verbeek, M. (2008). A guide to modern econometrics ( $3^{\text {rd }}$ edition). Chichester: John Wiley \& Sons Ltd.

Worthington, A. C. \& Pahlavani, M. (2007). Gold investment as an inflationary hedge: cointegration evidence with allowance for endogenous structural breaks. Applied Financial Economics Letters, 3, 259-262. http://dx.doi.org/10.1080/17446540601118301

Zakoïan, J. M. (1994). Threshold heteroskedastic models. Journal of Economic Dynamics and Control, 18, 931-944. http://dx.doi.org/10.1016/0165-1889(94)90039-6 